\title{
Unexplained postoperative retinal hemorrhage after 23-gauge sutureless vitrectomy
}

This article was published in the following Dove Press journal:

Clinical Ophthalmology

25 July $201 \mathrm{I}$

Number of times this article has been viewed

\author{
Hisato Ohno \\ Kenji Inoue \\ Inouye Eye Hospital, Tokyo, Japan
}

Correspondence: Hisato Ohno

Inoue Eye Hospital, 4-3 Kanda-Surugadai

Chiyoda-ku, Tokyo I0I-0062, Japan

Tel +8I 3329509 II

Fax +8I 332952150

Email oono-h@ka2.so-net.ne.jp
Abstract: We report five cases of unexplained retinal hemorrhage after 23-gauge sutureless vitrectomy. A 23-gauge sutureless vitrectomy was performed for four cases of macular holes $(\mathrm{MH})$ and one case of macular hole retinal detachment (MHRD). Retinal hemorrhages were observed on the first day after surgery and disappeared within several months without leaving any recognizable damage. We speculate that the retinal hemorrhages might have resulted from repeated collapse of the globe through a cannula under air perfusion, but other causes such as retinal vein congestion by face-down positioning are also possible.

Keywords: retinal hemorrhage, vitrectomy, postoperative, macular hole, sutureless surgery

\section{Introduction}

In microincision vitrectomy surgery (MIVS), the entrance incision at the conjunctiva and scleral wound is so small that wound suturing is unnecessary., ${ }^{1,2}$ Postoperative patient discomfort and astigmatism are less after MIVS than after 20-gauge standard vitrectomy and the postoperative recovery is faster. ${ }^{3}$

However, patients who undergo MIVS also have a higher risk of developing postoperative hypotony and endophthalmitis because of sutureless surgery. ${ }^{4}$ Various attempts to prevent these complications have been reported. ${ }^{5,6}$ As a result of these surgical modifications, the incidences of such complications have decreased markedly. ${ }^{?}$

The primary focus is directed toward preventing postoperative complications; however, little attention has been paid to the problematic use of cannulae.

We experienced five cases of retinal hemorrhages after 23-gauge sutureless vitrectomy that might have resulted from sharp intraocular pressure (IOP) fluctuations under air perfusion in the vitreous cavity.

\section{Case reports}

A 23-gauge vitrectomy using a cannula without a closure valve was performed to treat four cases of macular holes (MH) and one case of macular hole retinal detachment (MHRD). The internal limiting membrane (ILM) was peeled away from the inner retina over the entire macular area, using brilliant blue $\mathrm{G}(\mathrm{BBG})$ dye solution $(0.25 \mathrm{mg} / \mathrm{mL})$ (Sigma Aldrich, St Louis, MO) to stain the ILM. A fluid-air exchange was carried out with $30 \mathrm{~mm} \mathrm{Hg}$ of air perfusion pressure. At the end of surgery, 20\% SF6 gas for the $\mathrm{MH}$ or $12 \% \mathrm{C} 3 \mathrm{~F} 8$ gas for the MHRD was injected into the globe. Cataract surgery was simultaneously performed in all cases. 
A 67-year-old woman (Case 1) visited our clinic 4 months after she noticed blurred vision in her left eye. The visual acuity (VA) level of the left eye was $4 / 20$ at the initial visit. A stage II $\mathrm{MH}$ in her left eye was diagnosed by optical coherence tomography (OCT). A 23-gauge vitrectomy was performed. The globe collapsed when a perioperative instrument was inserted and removed after fluid-air exchange with $30 \mathrm{~mm} \mathrm{Hg}$ of air perfusion pressure. The IOP on the day after surgery was $16 \mathrm{mmHg}$, and the IOP values ranged between 10 and $16 \mathrm{mmHg}$ during the following 5-month observation period. $\mathrm{MH}$ closure was confirmed by postoperative OCT. Scattered intraretinal hemorrhages were identified in the fundus 1 day after surgery (Figure 1). The retinal hemorrhage completely resolved in about 2 months. Four months postoperatively, Goldmann perimetry showed no visual field constriction in that eye. In the other four cases, the collapse of the globes was similar to that in Case 1, and the hemorrhages resolved between 1 and 4 months in all cases without other complications. The IOPs were normal during the follow-up period in those four cases. Goldmann perimetry was within normal limits, similar to that in Case 1 (Table 1). In all patients, retinal hemorrhage was seen only in the operated eye, and the fellow eye was normal. Neither eye showed hemorrhage preoperatively.

\section{Discussion}

Regarding retinal hemorrhages related to sharp IOP fluctuations, Fechtner et al reported that a rapid drop in IOP after filtering glaucoma surgery may have caused the retinal hemorrhages, which the authors referred to as ocular decompression retinopathy. ${ }^{8}$ Following that report, similar cases were reported. Rezende et al reported two cases with retinal hemorrhages simulating decompression retinopathy

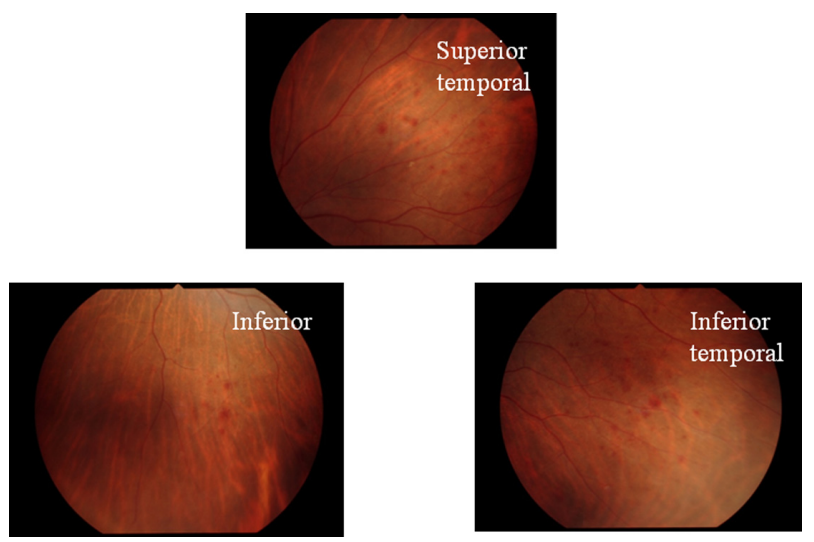

Figure I The retinal hemorrhage is observed over three quadrants in the fundus just after disappearance of the $20 \%$ SF 6 gas.

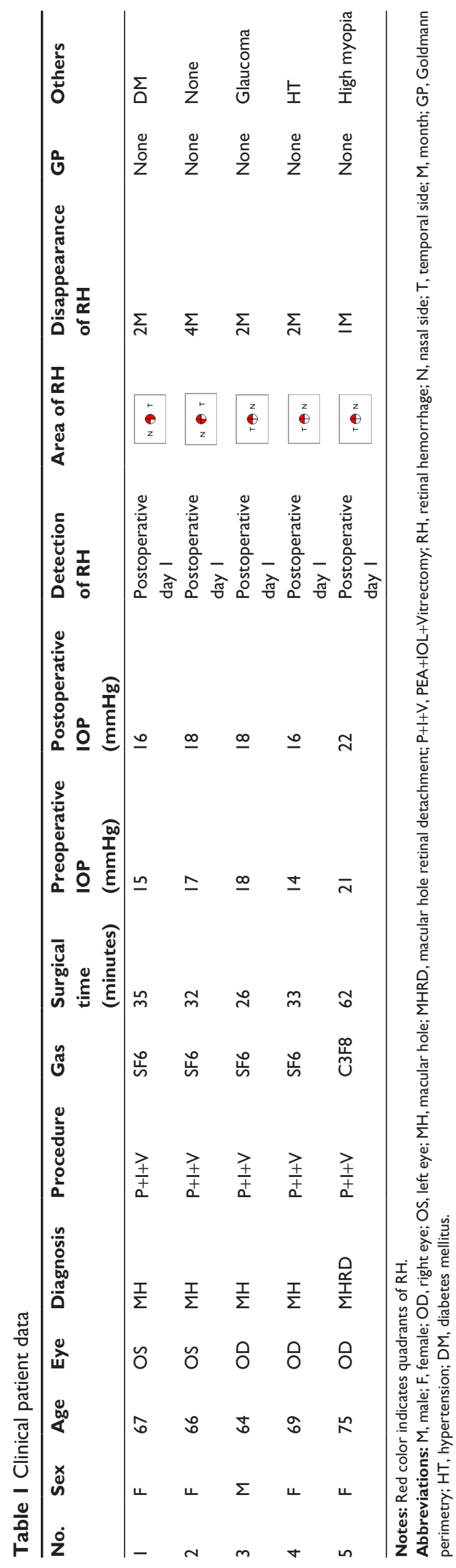


due to a rapid drop in postoperative IOP after 25-gauge sutureless vitrectomy. ${ }^{9}$ These procedures were performed for retained lens fragments and elevated IOP after complicated phacoemulsification. Unlike their report, in the current cases, fluid-air exchange was performed and the postoperative IOP values were within the normal range during the follow-up periods. We speculated that the dramatic drop in IOP due to the repeated collapse of the globe under air perfusion in the vitreous cavity might be one of the causes of the retinal hemorrhages. We also cannot exclude the possibility that the retinal hemorrhages might have been the initial sign of expulsive hemorrhage rather than decompression retinopathy. In addition, the possibilities of other causes, such as retinal vein congestion in the gas-filled globe due to face-down positioning, still remain. However, we did not experience such cases in conventional 20 -gauge vitrectomy for macular hole surgery.

The cannula system may have the advantages of a smaller incision and sutureless vitrectomy transconjunctivally, but the external and intraocular environments are directly connected through the cannula, which appears to cause a dramatic IOP drop when removing the instrument, especially under air perfusion conditions. We experienced similar conditions during conventional 20-gauge vitrectomy under air perfusion in cases where patients were inferred to have thin sclerae, such as in high myopia. However, we consider that a scleral wound in general may act as a loose-fit closure valve, in that the wound lets the fluid leak when intraocular pressure is high and stops the leak when it drops. In contrast, the placement of the cannula in the scleral wound renders it literally a "leak hole." Greater attention to pressure fluctuations is considered necessary in this situation. The dramatic IOP drop during surgery may result in retinal circulatory disturbances. Considering these results, lower perfusion pressure should be used and the perioperative IOP fluctuations kept to a minimum, especially in a vitreous cavity filled with air. We postulate that cannulae with a valve would be useful for blocking leak flow to maintain a relatively steady IOP.

Along with expanded indications for MIVS, ${ }^{10}$ maintenance of the integrity of a self-sealing wound and steady IOP values during vitreous surgery are important issues.

\section{Disclosure}

The authors report no conflicts of interest in this work.

\section{References}

1. Fujii GY, De Juan E Jr, Humayun MS, et al. A new 25-gauge instrument system for transconjunctival sutureless vitrectomy surgery. Ophthalmology. 2002;109(10):1807-1812.

2. Eckardt C. Transconjunctival sutureless 23 -gauge vitrectomy. Retina. 2005;25(2):208-211.

3. Okamoto F, Okamoto C, Sakata S, et al. Changes in corneal topography after 25-gauge transconjunctival sutureless vitrectomy versus after 20-gauge standard vitrectomy. Ophthalmology. 2007;114(12): 2138-2141.

4. Kunimoto DY, Kaiser RS. Wills Eye Retina Service. Incidence of endophthalmitis after 20- and 25-gauge vitrectomy. Ophthalmology. 2007;114(12):2133-2137.

5. Taban M, Sharma S, Ventura AA, Kaiser PK. Evaluation of wound closure in oblique 23-gauge sutureless sclerotomies with Visante optical coherence tomography. Am J Ophthalmol. 2009;147(1):101-107.

6. Shimada H, Nakashizuka H, Hattori T, Mori R, Mizutani Y, Yuzawa M. Conjunctival displacement to the corneal side for oblique-parallel insertion in 25-gauge vitrectomy. Eur J Ophthalmol. 2008;18(5): 848-851.

7. Shimada H, Nakashizuka H, Hattori T, Mori R, Mizutani Y, Yuzawa M. Incidence of endophthalmitis after 20- and 25-gauge vitrectomy: causes and prevention. Ophthalmology. 2008;115(12):2215-2220.

8. Fechtner RD, Minckler D, Weinreb RN, et al. Complications of glaucoma surgery. Ocular decompression retinopathy. Arch Ophthalmol. 1992;110(7):965-968.

9. Rezende FA, Regis LG, Kickinger M, Aicantara S. Decompression retinopathy after 25 -gauge transconjunctival sutureless vitrectomy: report of 2 cases. Arch Opthalmol. 2008;125(5):699-700.

10. Shimada H, Nakashizuka H, Mori R, Mizutani Y. Expanded indications for 25-gauge transconjunctival vitrectomy. Jpn J Ophthalmol. 2005; 49(5):397-401.
Clinical Ophthalmology

\section{Publish your work in this journal}

Clinical Ophthalmology is an international, peer-reviewed journal covering all subspecialties within ophthalmology. Key topics include: Optometry; Visual science; Pharmacology and drug therapy in eye diseases; Basic Sciences; Primary and Secondary eye care; Patient Safety and Quality of Care Improvements. This journal is indexed on

Submit your manuscript here: http://www.dovepress.com/clinical-ophthalmology-journal

\section{Dovepress}

PubMed Central and CAS, and is the official journal of The Society of Clinical Ophthalmology (SCO). The manuscript management system is completely online and includes a very quick and fair peer-review system, which is all easy to use. Visit http://www.dovepress.com/ testimonials.php to read real quotes from published authors. 